\title{
Concise Enantioselective Synthesis of Oxygenated Steroids via Sequential Copper(II)-Catalyzed Michael Addition/Intramolecular Aldol Cyclization Reactions
}

\author{
Nathan R. Cichowicz, Will Kaplan, Yaroslav Khomutnyk, Bijay Bhattarai, Zhankui Sun, and \\ Pavel Nagorny ${ }^{\star}$ \\ Department of Chemistry, University of Michigan, 930 N. University Avenue, Ann Arbor, MI 48109
}

\begin{abstract}
A new scalable enantioselective approach to functionalized oxygenated steroids is described. This strategy is based on chiral bis(oxazoline) copper(II) complex-catalyzed enantioselective and diastereoselective Michael reactions of cyclic ketoesters and enones to install vicinal quaternary and tertiary stereocenters. In addition, the utility of copper(II) salts as highly active catalysts for the Michael reactions of traditionally unreactive $\beta \beta^{\prime}$-enones and substituted $\beta \beta^{\prime}$-ketoesters that results in unprecedented Michael adducts containing vicinal all-carbon quaternary centers is also demonstrated. The Michael adducts subsequently undergo base-promoted diastereoselective aldol cascade reactions resulting in the natural or unnatural steroid skeletons. The experimental and computational studies suggest that the torsional strain effects arising from the presence of the $\Delta^{5}$ unsaturation are key controling elements for the formation of the natural cardenolide scaffold. The described method enables expedient generation of polycyclic molecules including modified steroidal scaffolds as well as challenging-to-synthesize Hajos-Parrish and Wieland-Miescher ketones.
\end{abstract}

\section{Keywords}

Steroids; Enantioselective Catalysis; Michael Reaction; Aldol Cyclization; Synthesis

\section{INTRODUCTION}

Steroids play an important role in drug discovery, medicinal chemistry, and chemical biology. These compounds are responsible for the regulation of vital biological functions in animals and plants, and, not surprisingly, the steroidal scaffold is a privileged motif that is present in many FDA-approved drugs. ${ }^{1}$ Developing means to access synthetic and natural steroids was one of the triumphs of last century's chemists, and the first total synthesis of a steroidal sex hormone, equilenin by Bachmann dates back to $1939 .{ }^{2}$ Despite major advances in the total synthesis of steroids, most steroid-based drugs are obtained by semi-synthesis using feedstock isolated from plant or animal sources. ${ }^{3}$ Recent developments in the field of

\footnotetext{
*Corresponding Author: nagorny@umich.edu.

Supporting Information Available.

Experimental procedures, ${ }^{1} \mathrm{H}$ and ${ }^{13} \mathrm{C}$ NMR spectra, and X-ray data are available free of charge via the Internet at http://pubs.acs.org.
} 
asymmetric catalysis have enabled the efficient preparation of simple enantioenriched steroids such as estrones. ${ }^{4}$ However, fewer asymmetric catalytic strategies for the construction of more complex steroids are available. In particular, despite the significant efforts invested in developing scalable synthetic routes to cardenolides, an asymmetric total synthesis of the steroids of this family still represent a formidable challenge. ${ }^{4-7}$ Considering recent interests in developing safer versions of existing medicines as well as the growing demand for cardenolide-based therapeutics, a concise, scalable and modular synthetic route to the cardenolide skeleton bearing necessary functionalization is highly desired. ${ }^{5 \mathrm{c}}$

This article describes a conceptually new asymmetric approach to steroids that enables rapid stereoselective synthesis of various cardenolide scaffolds. This approach relies on tandem asymmetric diastereoselective Michael addition/intramolecular aldol reactions to achieve expedient assembly of steroids. ${ }^{8-10}$ It requires simple and readily available building blocks 5 and $\mathbf{6}$, and achieves the synthesis of functionalized steroidal core 9 and the C13, C14epimeric core 8 in only $4-5$ steps (Figure 1). In addition, our method tolerates modifications in 5 and $\mathbf{6}$, which allows accomplishing rapid alterations in the ring size and C13substituents of $\mathbf{8}$ and $\mathbf{9}$. The scaffolds $\mathbf{8}$ and $\mathbf{9}$ are present in a variety of bioactive steroids (i.e. 1-4, Figure 1) and their quick generation provides exciting opportunities for the synthesis of these and many other natural and unnatural diterpenes.

Finally, the formation of the sterically strained chiral Michael adducts is described using a new variant of $\mathrm{Cu}$ (II)-catalyzed Michael reactions under solvent-free conditions.

Unprecedented Michael reactions with unreactive enones and ketoesters were achieved under these conditions, and applied to the preparation of chiral products with vicinal allcarbon quaternary centers and with vicinal quaternary and tertiary stereocenters is described. Development of this transformation not only enabled the four-step assembly of steroids, but also the asymmetric synthesis of functionalized Hajosh-Parrish and Wieland-Miescher ketones that are challenging to generate using existing methods.

\section{RESULTS AND DISCUSSION}

\section{Initial studies on Michael reaction}

As the asymmetric Michael reaction resulting in $\mathbf{7}$ is key to this approach, our studies commenced with investigating the addition of ketoester $\mathbf{6 a}$ to enone $\mathbf{5 a}$ (Table 1). Intermolecular Michael reactions of 2 -substituted $\beta$-ketoesters and $\beta$-substituted enones resulting in vicinal quaternary and tertiary stereocenters are challenging. ${ }^{11-13}$

Up to date, only the asymmetric catalytic transformations developed by Sodeoka's, Wang's, Ye's and Deng's groups describe the formation of these motifs with sufficiently high levels of enantiocontrol. ${ }^{14}$ However, the evaluation of the aforementioned methods using catalysts 10-12 (Table 1) ${ }^{12}$ did not result in significant formation of 7a, probably, due to the substantially lower reactivity of unactivated 6-membered $\beta$-ketoester $\mathbf{6 a}$. While catalyst $\mathbf{1 2}$ could indeed promote the previously reported reaction of $\mathbf{6 a}$ and methyl vinyl ketone to provide the corresponding Michael adduct in $77 \%$ yield, 36\% ee ( $c f$. Supporting Information), only $6 \%$ of $7 \mathbf{a}$ was detected by ${ }^{1} \mathrm{H}$ NMR analysis of the crude mixture after 72 $\mathrm{h}$ when ketone 5a was employed as an electrophile (entry 3 ). 
Considering that the prior methods were not suitable for the approach outlined in Figure 1, our further attempts were focused on identifying a new, more reactive catalytic system. Our initial efforts to form 7a with amine bases (entries 4-5) or LHMDS (not shown) were unsuccessful. However, in the following screening of the Lewis acid-based catalysts, we discovered that $\mathrm{Cu}(\mathrm{OTf})_{2}$ can promote an efficient Michael reaction ${ }^{15}$ between $\mathbf{6 a}$ and $\mathbf{5 a}$ in $86 \%$ yield, $4: 1$ d.r. (Table 1 , entry 8 ) under solvent free conditions. ${ }^{15 e}$ Interestingly, $\mathrm{Cu}(\mathrm{OTf})_{2}$ was unique in catalyzing the formation of $\mathbf{7 a}$. Thus, $\mathrm{Zn}(\mathrm{OTf})_{2}$ (entry 6) did not promote any reaction, and the use of $\operatorname{Sc}(\mathrm{OTf})_{3}$ (entry 7 ) led to decomposition of the starting materials. Furthermore, the diastereoselectivity of $\mathrm{Cu}(\mathrm{OTf})_{2}$-catalyzed reaction could be increased without affecting the yield if the reaction was run at $0{ }^{\circ} \mathrm{C}$ (entry 9 ).

\section{Developing asymmetric variant of Michael reaction}

With the racemic variant of this reaction in hand, we investigated the enantioselective variant of this transformation by employing chiral $\mathrm{Cu}$ (II) Box and PyBox complexes (Table 2). ${ }^{17}$ Such complexes have been previously employed as the catalysts for the conjugate additions of carbon and oxygen-based nucleophiles ${ }^{17}$ as well as Mukaiyama Michael reactions. ${ }^{18}$ The attempts of utilizing $\mathrm{Cu}(\mathrm{II})$ Box complexes for the direct Michael reactions of 1,3-dicarbonyls and enones are also documented $;{ }^{19}$ however, racemic products were observed in such cases. Thus, the only successful example of enantioselective Michael reaction catalyzed by $\mathrm{Cu}(\mathrm{II})$ Box complexes relied on activation of chelating electrophiles such as $\beta, \gamma$-unsaturated a-ketoesters. ${ }^{20}$

The optimization results for the enantioselective reaction of $\mathbf{6 a}$ and $5 \mathbf{a}$ resulting in chiral 7a are summarized in Table 2 . While $\mathrm{Cu}(\mathrm{OTf})_{2}$ complexes in some cases were found to promote enantioselective reaction (entries, 1 and 11), the complexes with non-coordinating counterions were found to be more reactive.(i.e. entry 1 vs. entry 2). Extensive evaluation of various Box and PyBox ligands, helped to identify 2,2'-(cyclopropane-1,1-diyl)bis(4phenyl-4,5-dihydrooxazole)-ligand $\mathbf{1 6} \mathbf{b}$ as the ligand of choice. ${ }^{21}$ Substantial ligand effects were observed in these studies, and no reaction was observed with Box ligands $\mathbf{1 3 b}$ and 13c despite our numerous attempts to optimize these reactions. The copper(II) hexafluoroantimonate complex of $\mathbf{1 6 b}$ promoted the formation of $\mathbf{7 a}$ at r.t. in $93 \%$ yield and good selectivity ( $5: 1 \mathrm{dr}, 84 \%$ ee). The enanti-oselectivity of this reaction was improved at lower temperature (entries 13 and 14), and under the optimal conditions (entry 13) the desired Michael adduct 7a was obtained in excellent yield and selectivity (89\% yield, 5:1 dr, $92 \%$ ee).

As the possibility of introducing substituents at the $\mathrm{C} 13$ position and changing A/D ring sizes in $\mathbf{7}$ is key to the approach outlined in Figure 1, the substrate scope of the enantioselective Michael reaction was investigated next (Scheme 1). With five-membered $\beta$ ketoesters, the reactions proceeded significantly faster $(24 \mathrm{~h})$ and with higher levels of diastereocontrol $(\mathbf{7 b}, \mathbf{7 c}, \mathbf{7 f}, \mathbf{7 g})$. For both 5- and 6-membered ketoesters, the alterations in the $\beta$-substituent of a $\beta$ unsaturated ketone portion of $\mathbf{5}$ were well tolerated, and substrates 7a-7i were obtained in good yields, diastereo- and enantioselectivities. 
Remarkably, the introduction of the vinyl chloride moiety into 6-membered ketoesters was also tolerated and the corresponding vinyl chloride-containing Michael adduct $7 \mathbf{i}$ was generated in excellent yield and selectivity. The presence of unsaturation resulted in significant enhancement in the d.r. of this reaction as a 14:1 mixture of diastereomers of $\mathbf{7 i}$ was obtained. The absolute and relative configurations of these adducts were later confirmed by X-ray crystallographic analysis of their cyclized products (Schemes 4 and 5). Thus, the absolute configuration of the series of Michael adducts 7 depicted in Scheme 2 can be achieved with $(R, R)-\mathbf{1 6 b}$. Importantly, getting access to 7a-7i in a highly selective manner was key to our synthetic plan outlined in Figure 1 and allowed us to further pursue the enantioselective synthesis of steroid analogs (Table 3).

The observations summarized in Table 1 suggest that $\mathrm{Cu}(\mathrm{II})$ salts are among the most active catalysts for the formation of sterically-strained Michael adducts such as 7a under solventfree conditions. In order to further demonstrate this point, Michael adducts $\mathbf{7 j}$ and $\mathbf{7 k}$ with vicinal all-carbon quaternary stereocenters were generated in good yields using $\mathbf{1 6 b}$ as the catalyst (Scheme 1). Due to the presence of unfavorable steric repulsions with the second $\beta$ substituent of the enone, these adducts were formed in lower enantioselectivities, and further optimization of the ligand would be required. At the same time, the ability to generate $\mathbf{7} \mathbf{j}$ and $7 \mathbf{k}$ using this method is of great utility by itself, considering that the formation of such Michael adducts with vicinal quaternary stereocenters is unprecedented under normal conditions, and the only existing reports describing similar transformations utilize stoichiometric base at ultra high pressures $(15 \mathrm{kBar}){ }^{16}$

The proposed mechanism of $\mathrm{Cu}(\mathrm{II})$-catalyzed Michael reaction is provided in Figure 2. Thus, $\mathrm{Cu}$ (II) undergoes chelation with the enol form of $\beta$-ketoester $\mathbf{6 a}$ to provide complex $\mathbf{I}$. Such complexes have previously been detected by ESI MS and proposed to be active complexes in $\mathrm{Cu}$ (II)-catalyzed Michael reactions. ${ }^{19 \mathrm{a}}$ This complex undergoes a Michael reaction with enone $\mathbf{5}$ to provide complex II. While some additional studies are required to clarify the details for the formation of complex II, coordination of $\mathbf{5}$ to $\mathrm{Cu}$ (II) followed by an intramolecular conjugate addition are proposed to be involved. The zwitterionic complex II then undergoes a proton transfer to generate complex III, which upon decomplexation regenerates $\mathbf{1 6 b}$.

\section{Double aldol cyclization studies}

With this key bond formation achieved, the double aldol cyclization strategy (Scheme 2) was investigated next. Depending on the sequence of the cyclization events, the formation of 8 from Michael adduct 7a can proceed via two different intermediates (i.e. 17a and 17b). It is noteworthy that the formation of steroid $\mathbf{8}$ results in four new stereogenic centers at the $\mathrm{C} 5, \mathrm{C} 8, \mathrm{C} 13$ and $\mathrm{C} 14$ positions. While the configuration of the $\mathrm{C} 5$ carbon will most likely be dictated by the adjacent $\mathrm{C} 10$ stereocenter regardless of the reaction pathway (i.e. 17a vs. 17b), the perspectives of achieving control over the configuration of the three remaining centers were not as clear. 
Moreover, the precedents established by the Deslong-champs group ${ }^{6 \mathrm{~b}}$ suggest that if the aldol cascade proceeds through $\mathbf{1 7} \mathbf{b}$ then the unnatural a-configuration of the $\mathrm{C} 13$ and $\mathrm{C} 14$ stereocenters is most likely to be formed (i.e. pro- $R$ ketone attack in $\mathbf{1 7 b}$ is preferred).

However, with no other precedents for the cyclization of 7a existing, we anticipated that the configuration at the $\mathrm{C} 8, \mathrm{C} 13$ and $\mathrm{C} 14$ carbons can be controlled with the proper selection of the aldolization conditions. Therefore, the following studies commenced with evaluation of various promoters and catalysts of aldol reactions (Table 3). The cyclization of 7a was unsuccessful under proline-catalyzed (entry 1 ) or soft enolization (entry 2 ) conditions. However, under the acidic conditions cyclization proceeded to provide enone $9 \mathbf{a}$ with the unnatural a-configuration of the C13- and C14-stereocenters (entry 3). Similarly, DBU- and piperidine-promoted transformations resulted in a clean formation of 8a (entries 4 and 5). The use of $\mathrm{LiCl}$ as an additive in combination with piperidine affected the outcome of this cyclization and enones $9 \mathbf{a}$ and $9 \mathbf{b}$ were formed along with $\mathbf{8 a}$ and $\mathbf{8 b}$ (entry 6). In our further attempts to improve the formation of $\mathbf{8 b}$ and $\mathbf{9 b}$, containing the desired natural stereochemistry, we investigated KHMDS-promoted cyclizations (entries 7 and 8). Remarkably, the temperature was found to be an important parameter, and when conducted in refluxing THF, only the natural $\beta$-diastereomers $\mathbf{9 b}$ and $\mathbf{9 c}$ were formed. To avoid deconjugation of $\mathbf{9 b}$ into $9 \mathbf{c}$ and to prevent retro-Michael pathway, a milder base, $\mathrm{Cs}_{2} \mathrm{CO}_{3}$, was employed at an elevated temperature $\left(140^{\circ} \mathrm{C}, \mathrm{DMF}\right)$. These conditions resulted in a fast formation of the desired enone $\mathbf{9 b}$ with the $\beta$-configuration of the $\mathrm{C} 13$ - and $\mathrm{C} 14-$ stereocenters of the CD-ring junction (entry 9).

\section{The origins of diastereodivergence in double aldol cyclization}

The results summarized in Table 3 indicate that in the case of the double aldol adducts $8 \mathbf{a}$ and $\mathbf{8 b}$ there is a clear preference for the pathway leading to the unnatural diastereomer $\mathbf{8 a}$ (Scheme 3). At the same time, elevated temperatures lead to the selective formation of natural diastereomer $\mathbf{9 b}$ containing $\Delta^{5}$-unsaturation. These results are consistent with the mechanistic pathway, in which the B-ring is closed first. In the case of the reactions catalyzed by DBU or $p$-TSA (entries 3 and 4), the second aldol addition proceeds through $18 \mathbf{a}$ and $18 \mathrm{~b}$ and leads to $8 \mathbf{a}$ or $8 \mathbf{b}$, and the pathway from 18a to $8 \mathbf{a}$ is energetically more favored. Indeed, computations (DFT, geometry optimization, B3LYP, 6-31+G*) suggest that $8 \mathbf{a}$ is more stable than $\mathbf{8 b}$ by $1.8 \mathrm{kcal} / \mathrm{mol}$. However, the reaction promoted by $\mathrm{Cs}_{2} \mathrm{CO}_{3}$ at $140{ }^{\circ} \mathrm{C}$ (entry 9) is likely to proceed through a different mechanism, in which the intermediate al-dol adduct $\mathbf{1 8 b}$ undergoes elimination of water to form the corresponding aldol condensation product 20 ( $c f$. Eq. 1). This product then cyclizes via 19a and 19b to form $9 \mathbf{a}$ and $9 \mathbf{b}$. With the $\Delta^{5}$-unsaturation, the natural configuration present in $9 \mathbf{b}$ becomes more stable, and thus the pathway proceeding through $19 \mathrm{~b}$ becomes more energetically favored. The observed preference for $\mathbf{9 b}$ can possibly be the result of not only kinetic, but also thermodynamic control. Consistent with this proposal, the computational studies suggest that the energy of the enone $\mathbf{9 b}$ with natural configuration is $2.1 \mathrm{kcal} / \mathrm{mol}$ lower than the energy of the unnatural enone 9a. We propose that formation of the C5-C6 enone double bond in ring $\mathrm{B}$, results in increased torsional strain for the unnatural a-configuration, and for the diastereomeric enones $\mathbf{9 a} / \mathbf{9 b}$, the natural $\beta$-diastereomer $\mathbf{9 b}$ becomes more stable. ${ }^{6 \mathrm{~h}}$ 

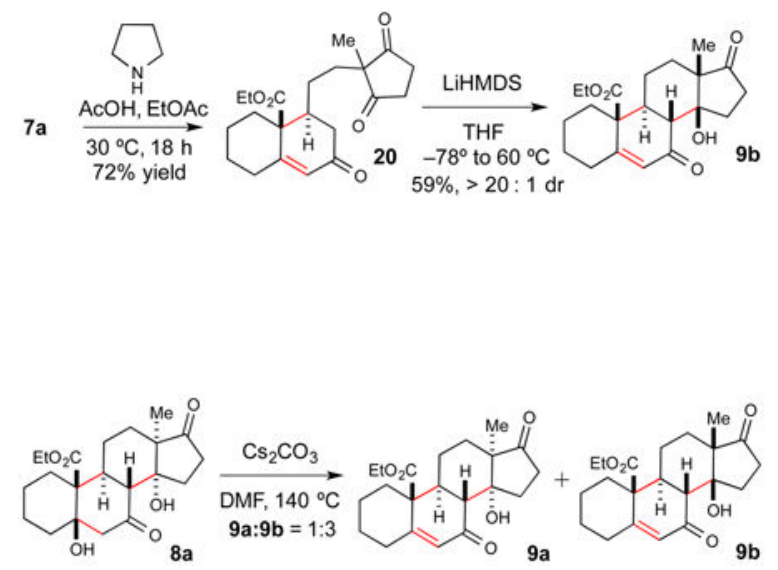

To validate the mechanistic proposal above, the experiments depicted in equations 1 and 2 were performed. Enone $\mathbf{2 0}$ was prepared by pyrrolidine-promoted monocyclization of 7a. This compound was treated with LiHMDS, which produced $\mathbf{9 b}$ as the only observed product (>20:1 dr after $30 \mathrm{~min}$, Eq. 1). In an additional control experiment, diastereomerically pure adduct $8 \mathbf{a}$ was treated with $\mathrm{Cs}_{2} \mathrm{CO}_{3}$ at $140{ }^{\circ} \mathrm{C}$ (Eq. 2). As expected, 8a underwent elimination of water, and 1:3 mixture of 9a:9b was observed under the reaction conditions. The outcome of this experiment suggests that the formation of $9 \mathbf{a}$ and $9 \mathbf{b}$ may be reversible at $140{ }^{\circ} \mathrm{C}$. However, considering that significant quantities of $9 \mathrm{a}$ were observed along with $\mathbf{9 b}$, the exclusive formation of $\mathbf{9 b}$ observed for the direct cyclization of $\mathbf{7 a}$ (entry 9, Table 3) cannot be a sole result of the thermodynamically controlled isomerization of $9 \mathbf{a}$ into $\mathbf{9 b}$.

\section{Application to the synthesis of natural and unnatural cardenolides}

The formation of unnatural steroids 8a-8g from the corresponding Michael adducts (7a-7f) was investigated next (Scheme 4). Based on the results summarized in Table 3, DBU was selected as the base of choice to promote these cyclizations. Upon subjecting 7a-7f to DBU in refluxing THF, the cyclizations proceeded cleanly and resulted in the formation of the corresponding steroids with the epimeric a-CD-ring junction. In all cases, the epimeric steroids were obtained in excellent yields and selectivities, and the formation of the otherwise challenging to generate by semi-synthesis $8 \mathbf{a}, \mathbf{8 d}$ and $8 \mathbf{e}$ as well as C13-ethyl group containing products $\mathbf{8 c}$ and $\mathbf{8 f}$ was successfully achieved. The relative configurations of compound $\mathbf{8 a}$ and the relative and absolute configuration of $\mathbf{8 d}$ were assigned based on $\mathrm{X}$-ray crystalographic analysis ( $c f$. Scheme 4 ). It is also noteworthy that all of these compounds were generated via 4-step linear sequences from the commercially available building blocks.

To demonstrate that our method could be used for the generation of steroids with natural cardenolide configuration, chiral steroid $\mathbf{9 b}$, as well as enones $\mathbf{2 1}$, and $\mathbf{2 2}$ were formed from the corresponding Michael adducts (conditions A and B, Scheme 5). It is noteworthy that the formation of $\mathbf{9 b}$ was carried on a $1.5 \mathrm{~g}$ scale without significant erosion in yield and 
enantioselectivity, and its absolute and relative configuration was confirmed by X-ray crystallographic analysis. Compound $\mathbf{9 b}$ possesses all of the necessary functionalities and stereochemistry to be converted to cardenolides as well as other steroids, and the efforts in this direction are ongoing in our laboratories.

A two-step protocol (conditions B) was required for the clean formation of $\mathbf{2 1}$ and $\mathbf{2 2}$ as the corresponding cyclizations with $\mathrm{Cs}_{2} \mathrm{CO}_{3}$ at $140{ }^{\circ} \mathrm{C}$ resulted in significant amounts of retroMichael products. To circumvent this problem, the Michael adducts $\mathbf{7 b}$ and $\mathbf{7 d}$ were monocyclized with pyrrolidine acetate (i.e. conditions resulting in the formation of enamine) to afford a clean formation of the corresponding $\Delta^{5}$-enones. As in the case of the cyclization described in equation 1, the following treatment of the monocyclized enone with LiHMDS (21) or NaHMDS (22) resulted in a clean diastereoselective formation of the corresponding cardenolide analog with the natural configuration.

As a result, the corresponding steroids $\mathbf{2 1}$ and $\mathbf{2 2}$ were obtained in 35\% and 39\% (2 steps), correspondingly, starting with the diastereomeric mixtures of the corresponding Michael adducts. Importantly, the semi-synthetic methods based on the modification of the natural steroids would not provide a straightforward access to analogs such as $\mathbf{2 1}$ and $\mathbf{2 2}$, while our current approach permitted an expedient generation of these scaffolds in only 5 steps from the commercially available starting materials.

Finally, the formation of substituted Hajosh-Parrish and Wieland-Miescher ketones ${ }^{22}$ by the cyclization of Michael adducts $\mathbf{7 g}$ and $\mathbf{7 h}$ (conditions $\mathrm{C}$ ) was performed to provide enones 23 and 24. Such enones (and $\mathbf{2 4}$ in particular) contain adjacent quaternary/tertiary stereocenters and to our knowledge are not readily obtained enantioselectively. ${ }^{23}$

\section{SUMMARY AND CONCLUSIONS}

In conclusion, a new method for a rapid assembly of natural and unnatural cardenolide skeletons has been developed. This method is enabled by developing a new chiral bis(oxazoline) copper(II) complex-catalyzed enantioselective and diastere-oselective Michael reaction of cyclic ketoesters and enones to install vicinal quaternary and tertiary C9- and C10-stereocenters. These products subsequently undergo base-promoted diastereoselective aldol cascade reactions resulting in the natural or unnatural steroid skeletons. The mechanistic studies suggest that the stereodivergence in the cyclization step arises from the torsional effects that favor a thermodynamically more stable natural configuration-containing ring system $\mathbf{9 b}$ at the elevated temperatures. The described method enables expedient generation of polycyclic molecules including modified steroidal scaffolds and challenging-to-synthesize substituted Hajos-Parrish and Wieland-Mischer ketones. It is also noteworthy that the developed in these studies $\mathrm{Cu}$ (II)-catalyzed Michael reaction represents one of the most powerful transformations of this type displaying great tolerance to steric bulk of both nucleophiles and electrophiles. Thus, the work described herein suggests that this method is among the best asymmetric methods for the formation of the Michael adducts containing vicinal quaternary and tertiary stereocenters. In addition, the application of this new protocol allowed the unprecedented under normal conditions preparation of Michael adducts $\mathbf{7} \mathbf{j}$ and $\mathbf{7 k}$ containing vicinal quaternary stereocenters. The 
further application of this method to the synthesis of natural and unnatural steroids and diterpenes is the subject of ongoing studies in our laboratory.

\section{Supplementary Material}

Refer to Web version on PubMed Central for supplementary material.

\section{Acknowledgments}

\section{Funding Sources and Acknowledgement}

This work was supported by NIGMS R01 grant (1R01GM111476-01). PN is a Sloan Foundation Fellow. W.K. is the AFPE and the University of Michigan CBI training program fellow (NIH grant 5T32GM008597). We thank prof. Edwin Vedejs for the useful suggestions during the preparation of this manuscript. We acknowledge funding from NSF grant CHE-0840456 for X-ray instrumentation.

\section{References}

1. (a) Corey, EJ.; Czako, B.; Kurti, L. Molecules and medicine. Hoboken, NJ: Wiley; 2007. (b) Newman DJ, Cragg GM. J Nat Prod. 2012; 75:311. [PubMed: 22316239]

2. Bachmann WE, Cole W, Wilds AL. J Am Chem Soc. 1939; 61:974.

3. (a) Thomas R, Boutagy J, Gelbart A. J Pharm Sci. 1974; 63:1651.(b) Wang, F-Q.; Yao, K.; Wei, DZ. Soybean and Health. El-Shemy, H., editor. In Tech; 2011.

4. Selected approaches: Danishefsky SJ, Cain P. J Am Chem Soc. 1976; 98:4975. [PubMed: 950420] Yeung YY, Chein RJ, Corey EJ. J Am Chem Soc. 2007; 129:10346. [PubMed: 17672468] Schotes C, Althaus M, Aardoom R, Mezzetti A. J Am Chem Soc. 2012; 134:13331.Prevost S, Dupre N, Leutzsch M, Wang Q, Wakchaure V, List B. Angew Chem Int Ed. 2014; 53:8770.Halskov KS, Donslund BS, Barfusser S, Jorgensen KA. Angew Chem Int Ed. 2014; 53:4137.

5. (a) Wiesner K, Tsai TYR. Pure \& Appl Chem. 1986; 58:799.(b) Heasley B. Chem Eur J. 2012; 18:3092. [PubMed: 22354477]

6. Selected approaches to cardenolides: Yoshii E, Oribe T, Tumura K, Koizumi T. J Org Chem. 1978; 43:3946.Lavallee JF, Deslongchamps P. Tetrahedron Lett. 1988; 29:6033.Deng W, Jensen MS, Overman LE, Rucker PV, Vionnet JP. J Org Chem. 1996; 61:6760. [PubMed: 11667560] Stork G, West F, Lee HY, Isaacs RCA, Manabe S. J Am Chem Soc. 1996; 118:10660.Overman LE, Rucker PV. Tetrahedron Lett. 1998; 39:4643.Jung ME, Davidov P. Angew Chem Int Ed. 2002; 41:4125.Honma M, Nakada M. Tetrahedron Lett. 2007; 48:1541.Mukai K, Urabe D, Kasuya S, Aoki N, Inoue M. Angew Chem Int Ed. 2013; 52:5300.

7. Ouabagenin synthesis: Zhang H, Reddy MS, Phoenix S, Deslongchamps P. Angew Chem Int Ed. 2008; 47:1272.Reddy MS, Zhang H, Phoenix S, Deslong-champs P. Chem-Asian J. 2009; 4:725. [PubMed: 19294722] Renata H, Zhou Q, Baran PS. Science. 2013; 339:59. [PubMed: 23288535] Renata H, Zhou Q, Dunstl G, Felding J, Merchant RR, Chien-Hung Y, Baran PS. J Am Chem Soc. 2015; 137:1330. [PubMed: 25594682] Mukai K, Kasuya S, Nakagawa Y, Urabe D, Inoue M. Chem Sci. 2015; 6:3383.

8. Conjugate addition/intramolecular aldolization studies: Matsuda I, Takahashi K, Sato S. Tetrahedron Lett. 1990; 31:5331.Baik TG, Luis AL, Wang LC, Krische MJ. J Am Chem Soc. 2001; 123:6716. [PubMed: 11439068] Jang HY, Huddleston RR, Krische MJ. J Am Chem Soc. 2002; 124:15156. [PubMed: 12487574] Agapiou K, Cauble DF, Krische MJ. J Am Chem Soc. 2004; 126:4528. [PubMed: 15070365]

9. Stereoselective Michael reactions in the synthesis of complex terpenoids: Movassaghi M, Tjandra M, Qi J. J Am Chem Soc. 2009; 131:9648. [PubMed: 19555115] Larson RT, Clift MD, Thomson RJ. Angew Chem Int Ed. 2012; 51:2481.Evans DA, Adams DJ, Kwan EE. J Am Chem Soc. 2012; 134:8162. [PubMed: 22533781] Xiao Q, Jackson JJ, Basak A, Bowler JM, Miller BG, Zakarian A. Nature Chemistry. 2013; 5:410.

10. Our prior studies on modular assembly of natural products: Cichowicz N, Nagorny P. Org Lett. 2012; 14:1058. [PubMed: 22292860] 
11. (a) Bergmann ED, Ginsburg D, Pappo R. Organic Reactions, Chapter. 2011; 3:182-542.(b) Alonso, DA. Organo-catalyzed conjugate additions. In: Mahrwald, R., editor. Enantioselective Organocatalyzed Reactions II. Springer; 2011.

12. (a) Douglas CJ, Overman LE. Proc Natl Acad Scie USA. 2004; 101:5363.(b) Overman LE, Quasdorf KW. Nature. 2014; 516:181. [PubMed: 25503231] (c) Liu Y, Han SJ, Liu WB, Stoltz BM. Acc Chem Res. 2015; 48:740. [PubMed: 25715056]

13. Enantioselective allylations: Reeves CM, Behenna DC, Stoltz BM. Org Lett. 2014; 16:2314. [PubMed: 24724872] Liu WB, Reeves CM, Virgil SC, Stoltz BM. J Am Chem Soc. 2013; 135:10626. [PubMed: 23829704] Liu WB, Reeves CM, Stoltz BM. J Am Chem Soc. 2013; 135:17298. [PubMed: 24160327]

14. (a) Hamashima Y, Hotta D, Sodeoka M. J Am Chem Soc. 2002; 124:11240. [PubMed: 12236717] (b) Hamashima Y, Hotta D, Umebayashi N, Tsuchiya Y, Suzuki T, Sodeoka M. Adv Synth Cat. 2005; 347:1576.(c) Yang J, Li W, Jin Z, Liang X, Ye J. Org Lett. 2010; 12:5218. [PubMed: 20954724] (d) Wang J, Li H, Zu L, Jiang W, Xie H, Duan W, Wang W. J Am Chem Soc. 2006; 128:12652. [PubMed: 17002351] (e) Wu F, Hong R, Khan J, Liu X, Deng L. Angew Chem Int Ed. 2006; 45:4301.

15. Cu(II)-catalyzed Michael reactions: Saegusa T, Ito Y, Tomita S, Kinoshita H. Bull Chem Soc Jpn. 1972; 45:496.Desimoni G, Quadrelli P, Righetti PP. Tetrahedron. 1990; 46:2927.Christoffers J, Mann A. Angew Chem Int Ed. 2000; 39:2752. Yadav JS, Reddy BVS, Baishya G, Narsaiah VA. Chemistry Lett. 2005; 34:102.Mekonnen A, Carlson R. Eur J Org Chem. 2006:2005.Perez E, Moreno-Manas M, Sebastian RM, Vallribera A, Jutand A. Eur J Inorg Chem. 2010:1013.Oe K, Ohfune Y, Shinada T. Org Lett. 2014; 16:2550. [PubMed: 24742128]

16. (a) Dauben WG, Bunce RA. J Org Chem. 1983; 48:4642.(b) Dauben WG, Gerdes JM. Tetrahedron Lett. 1983; 24:3841.

17. Reviews: Desimoni G, Faita G, Jorgensen KA. Chem Rev. 2011; 111:PR284. [PubMed: 22077602] Alexakis A, Backvall JE, Krause N, Pamies O, Dieguez M. Chem Rev. 2008; 108:2796. [PubMed: 18671436] Desimoni G, Faita G, Jorgensen KA. Chem Rev. 2006; 106:3561. [PubMed: 16967916] Comelles J, Moreno-Manas M, Vallribera A. ARKIVOC. 2005:207.

18. $\mathrm{Cu}(\mathrm{II}) \bullet B o x$ complex-catalyzed enantioselective Mukaiyama Michael reactions: Evans DA, Rovis T, Johnson JS. Pure Appl Chem. 1999; 71:1407.Evans DA, Rovis T, Kozlowski MC, Tedrow JS. J Am Chem Soc. 1999; 121:1994.Johnson JS, Evans DA. Acc Chem Res. 2000; 33:325. [PubMed: 10891050] Evans DA, Scheidt KA, Johnston JN, Willis MC. J Am Chem Soc. 2001; 123:4480. [PubMed: 11457234] Cu(II)•Box complex-catalyzed enantioselective aza-Michael reactions: Palomo C, Oiarbide M, Halder R, Kelso M, Gomez-Bengoa E, Garcia JM. J Am Chem Soc. 2004; 126:9188. [PubMed: 15281801] Yamazaki S, Yamamoto M, Sumi A. Tetrahedron. 2007; 63:2320.Nakama K, Seki S, Kanemasa S. Tetrahedron Lett. 2002; 43:829.Cornminboeuf O, Quranta L, Renaud P, Liu M, Jasperse CP, Sibi MP. Chem-Eur J. 2003; 9:29.Sibi MP, Liu M. Org Lett. 2001; 3:4181. [PubMed: 11784172]

19. Prior attempts to accomplish direct $\mathrm{Cu}$ (II)•Box complex-catalyzed enantioselective Michael reactions of 1,3-dicarbonyls and enones resulting in unselective reactions: Comelles J, MorenoManas M, Perez E, Roglans A, Sebastian RM, Vallribera A. J Org Chem. 2004; 69:6834. [PubMed: 15387609] Zhang M, Liu N, Tang W. J Am Chem Soc. 2013; 135:12434. [PubMed: 23930656]

20. Halland N, Velgaard T, Jorgensen KA. J Org Chem. 2003; 68:5067. [PubMed: 12816459]

21. Wong A, Welch CJ, Kuethe JT, Vazquez E, Shaimi M, Henderson D, Davies IW, Hughes D. L Org Biomol Chem. 2004; 2:168.

22. Bradshaw B, Bonjoch J. Synlett. 2012; 23:337.

23. The only existing asymmetric synthesis of Hajosh-Parrish ketone similar to $\mathbf{2 3}$ is described in reference 14b. To our knowledge the asymmetric synthesis of the substituted Wieland-Miesher ketones such as $\mathbf{2 4}$ is unprecedented. 

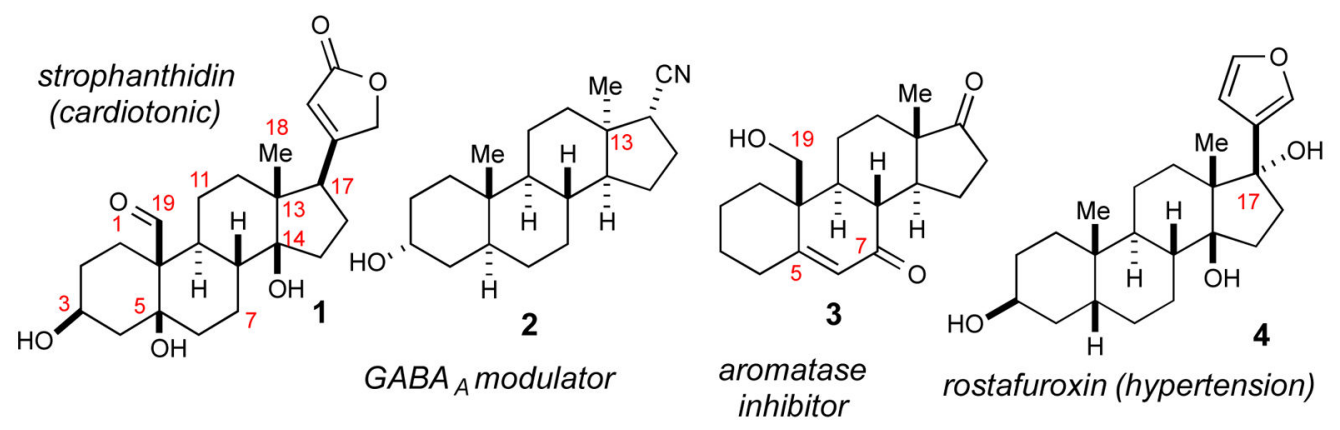

Enantioselective Michael/Double Aldol Approach<smiles>O=C1CCCCC1C1CCCCC1</smiles>



$+$<smiles>[10BH]</smiles><smiles>[R][C@H](C)OCC</smiles><smiles>C=CC(C)=O</smiles>

$\mathrm{R}=\mathrm{Me}$ or $\mathrm{Et}$
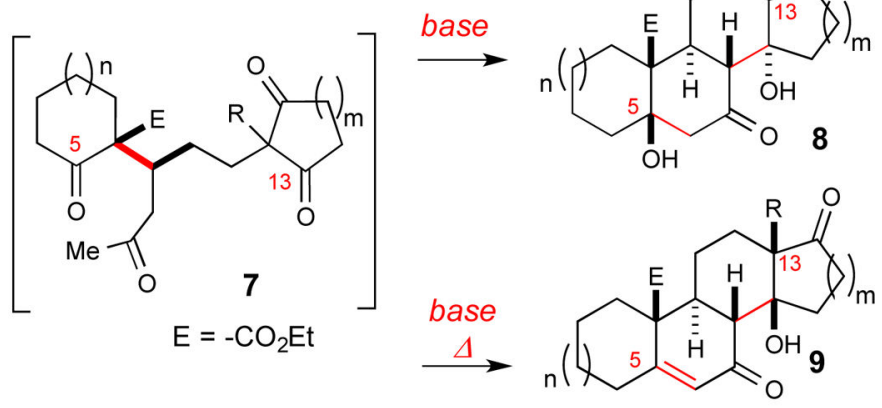

Figure 1.

Approach Summary 


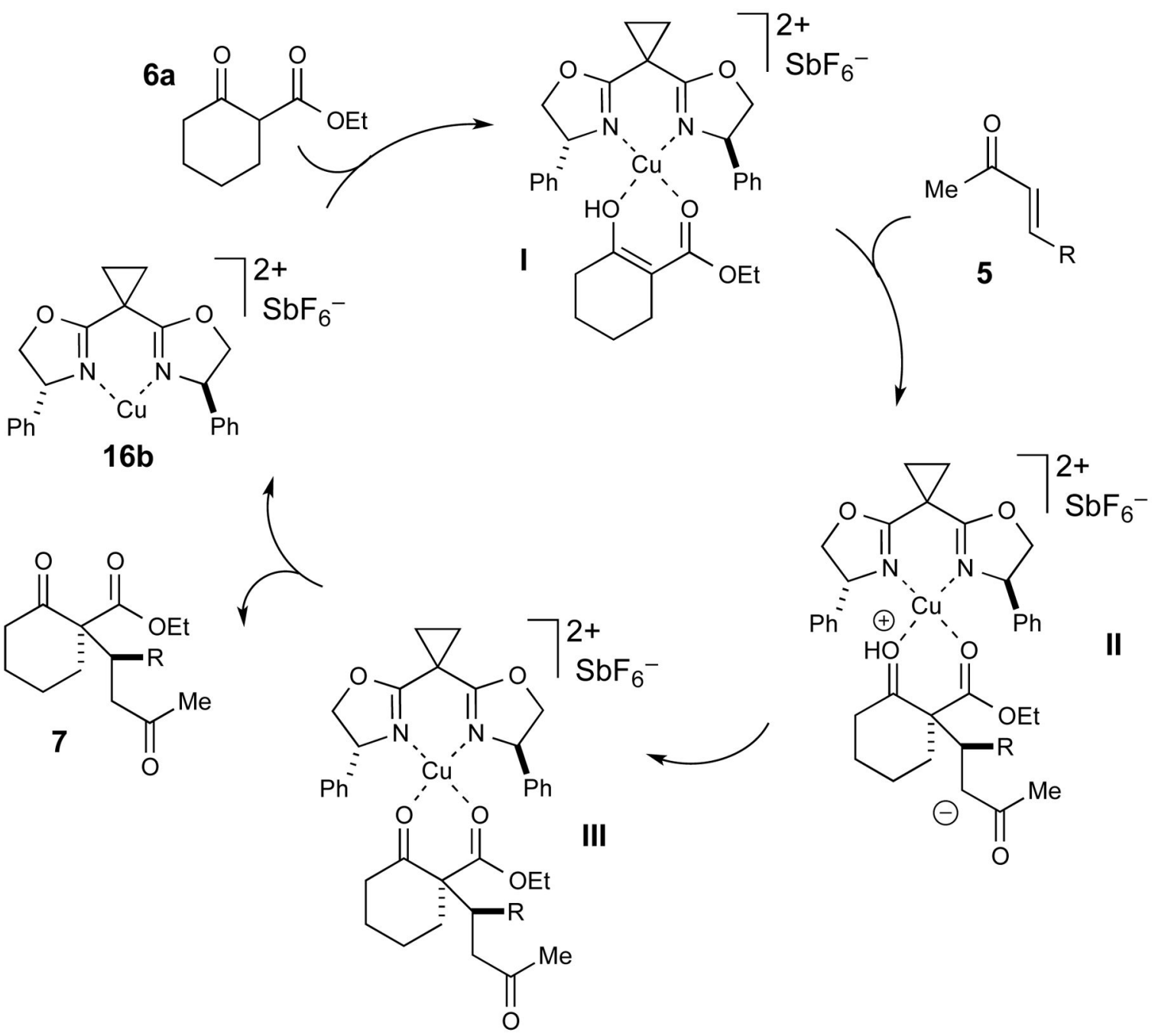

Figure 2.

Tentative Mechanism of $\mathrm{Cu}$ (II)-Catalyzed Michael Reaction 

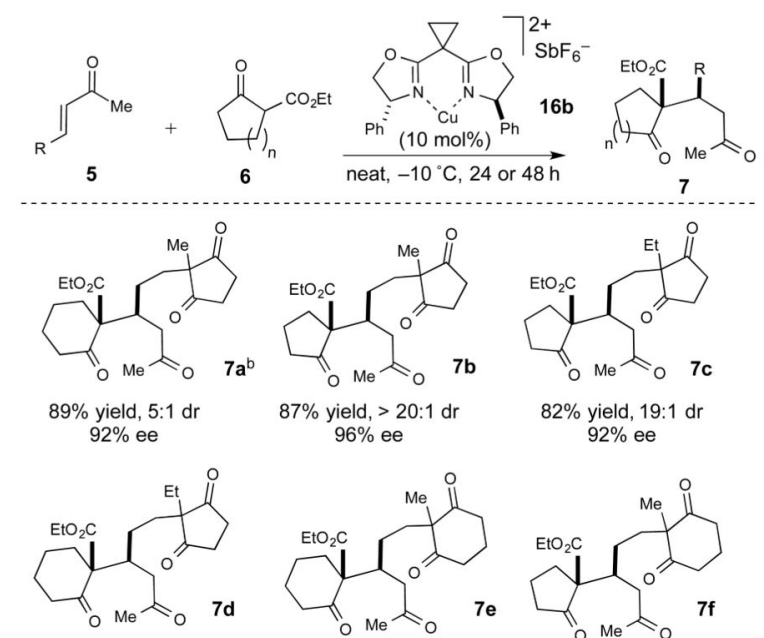

$96 \%$ ee $92 \%$ ee

$93 \%$ yield, $4: 1 \mathrm{dr}$
$90 \%$ ee

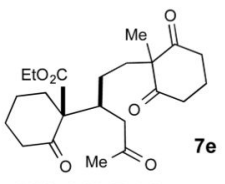

$88 \%$ yield, $7: 1 \mathrm{dr}$
$91 \%$ ee
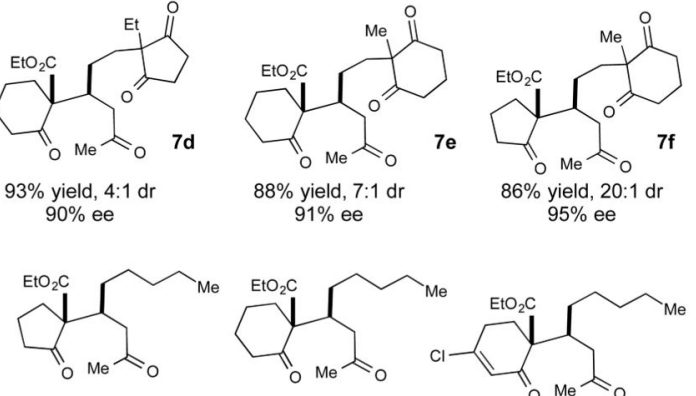

$7 \mathrm{~h}$

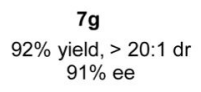

$95 \%$ yield, $10: 1 \mathrm{dr}$

$94 \%$ ee
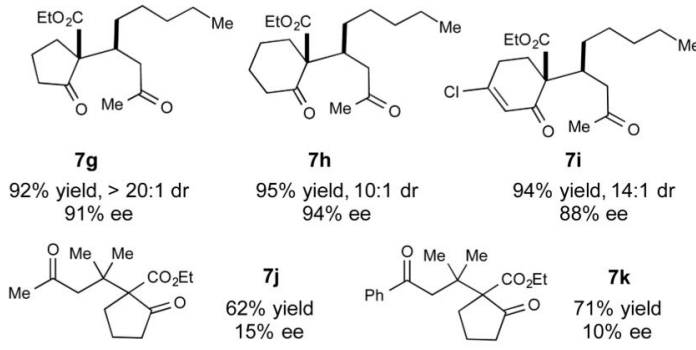

\section{Scheme 1.}

Substrate scope of the enantioselective Michael reaction ${ }^{\mathrm{a}}$

${ }^{a}$ Reactions were performed on $0.82-1.3 \mathrm{mmol}$ scale. The depicted absolute stereochemistry of $\mathbf{7 a}-7 \mathbf{h}$ could be achieved with $(R, R)-\mathbf{1 6} \mathbf{b}$. The yields and selectivities represent an average of two runs. The d.r. is determined by ${ }^{1} \mathrm{H}$ NMR analysis. ${ }^{b}$ This reaction was also performed on $10.8 \mathrm{mmol}$ scale ( $c f$. Scheme 5 and $\mathrm{SI}$ ) 


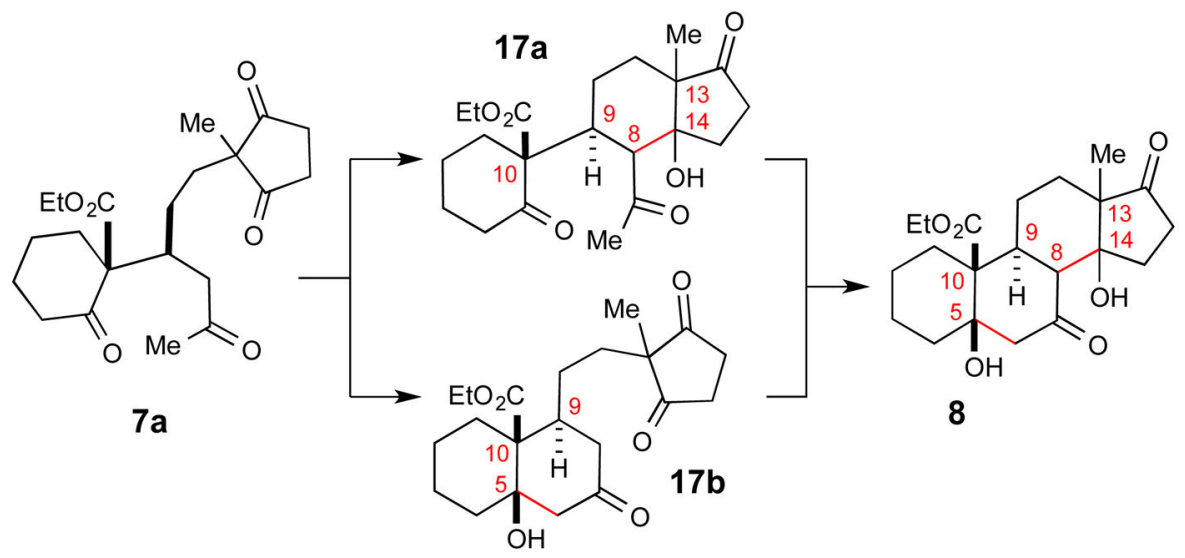

Scheme 2.

Proposed double cyclization strategy 


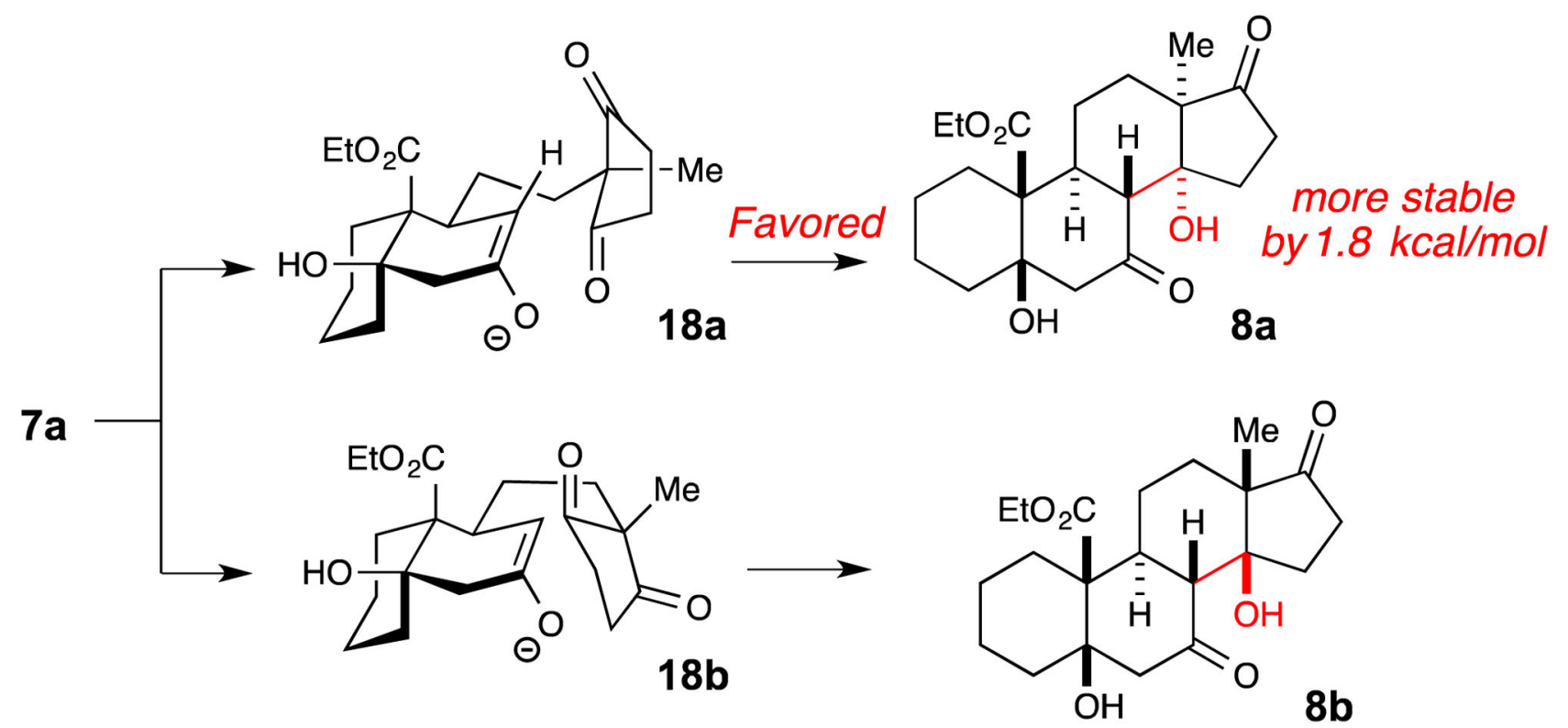

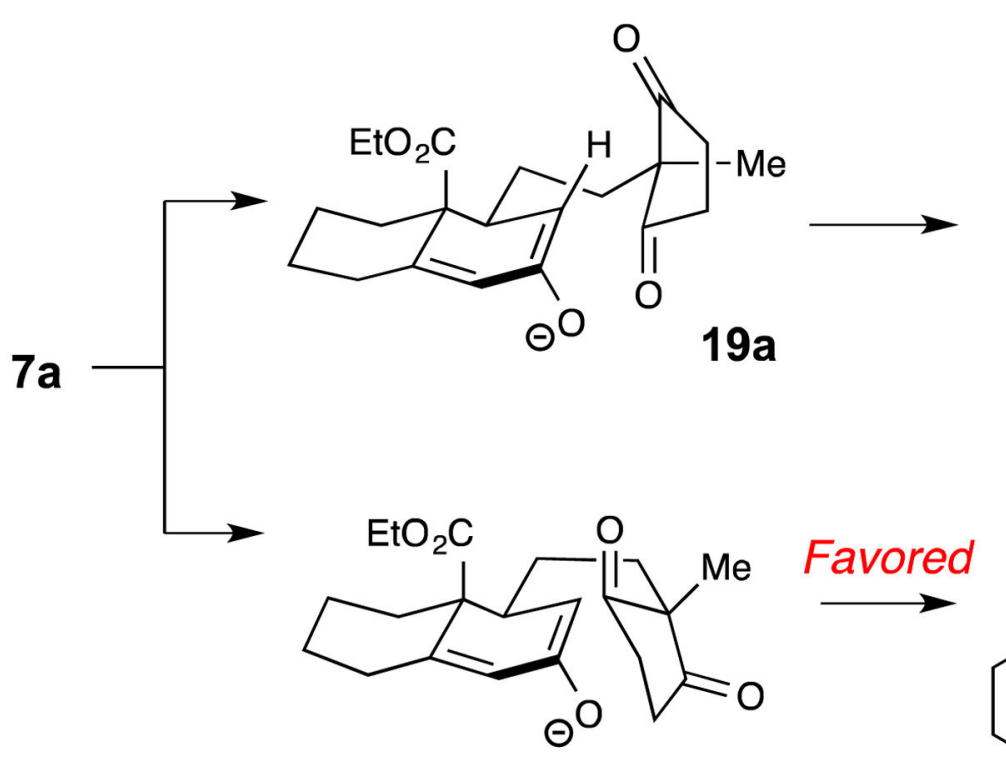

$19 b$<smiles>CCO[C@]12CCCCC1=CC(=O)[C@@H]1[C@@H]2CC[C@@]2(C)C(=O)CC[C@@]12O</smiles><smiles>[M]C1CC[C@@H]2[C@H](C(=O)C=C3CCCC[C@@]32C)[C@H]1O</smiles>

Scheme 3.

Explaination of diastereoselectivity for the formation of $\mathbf{8 a - 9 b}$ 

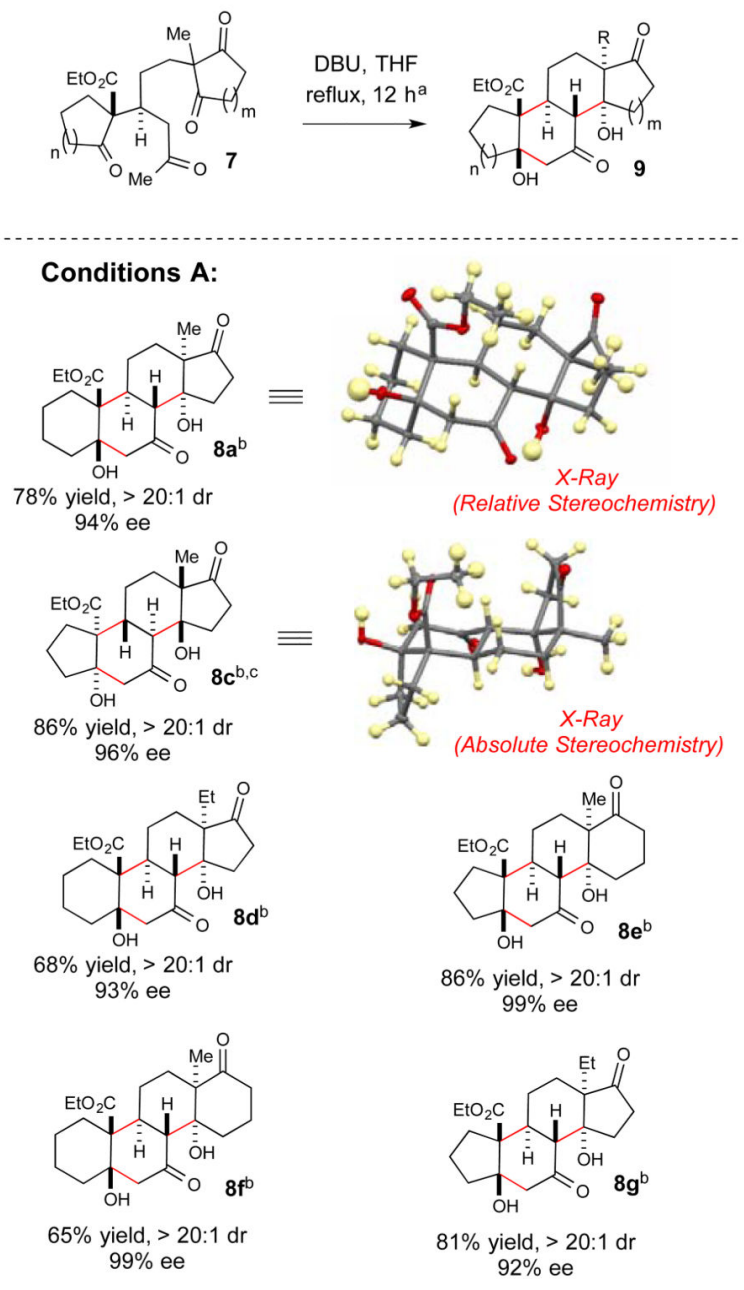

Scheme 4.

Diastereoselective formation of steroids with unnatural configuration

${ }^{\text {aS Substrates }} 7$ were used as the diastereomeric mixtures of Michael adducts (cf. Scheme 1) without pre-separation of the minor diastereomers. 7 were treated with DBU, THF, reflux, $12 \mathrm{~h}$. ${ }^{\mathrm{b}}$ The yields are reported for the isolated major diastereomer after purification by chromatography. $(R, R)$-enantiomer of $\mathbf{1 6} \mathbf{b}$ was used to generate the depicted enantiomers of 8. ${ }^{\mathrm{c}}(S, S)$-enantiomer of $\mathbf{1 6 b}$ was used to generate the depicted enantiomers of $\mathbf{8 c}$. 


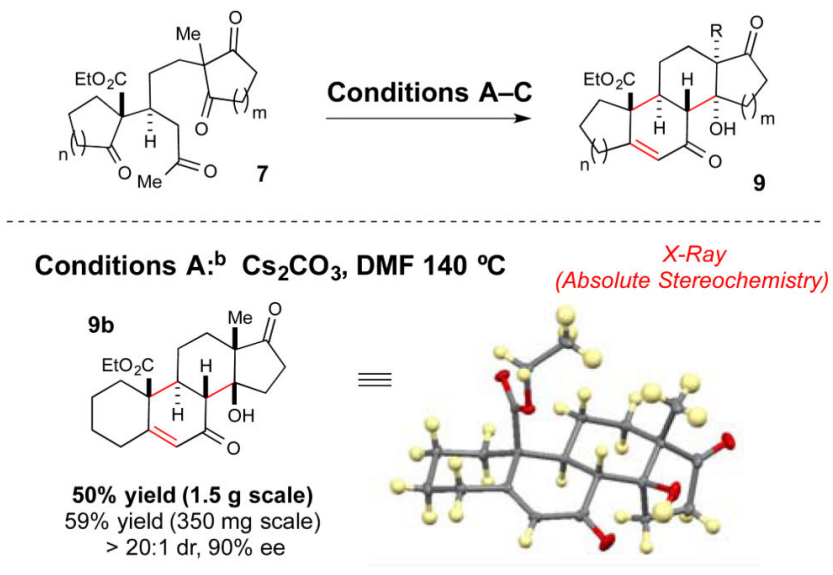

Conditions B: ${ }^{c}$ a) Pyrrolidine, HOAc; b) LiHMDS or NaHMDS



Conditions C: ${ }^{\text {d }}$ Pyrrolidine, HOAC

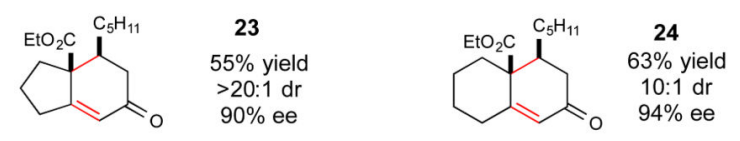

\section{Scheme 5.}

Diastereoselective formation of steroids with the natural configuration ${ }^{\text {a }}$

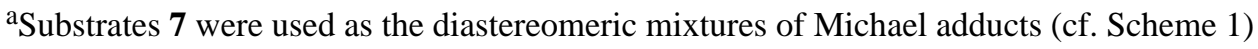
without pre-separation of the minor diastereomers. The reactions were complete and the yields are based on the isolated diastereomerically pure 9b, 21-24 after purification.

Condition A:. $\mathrm{Cs}_{2} \mathrm{CO}_{3}, \mathrm{DMF}, 140{ }^{\circ} \mathrm{C}, 1 \mathrm{~h}$; ${ }^{\text {b}}$ Condition B: i) Pyrrolidine (1 equiv), AcOH (1 equiv), EtOAc, $30{ }^{\circ} \mathrm{C}, 20$ h; ii) LHMDS/THF (21) or NaHMDS/toluene (22), reflux; ${ }^{\mathrm{c} C o n d i t i o n} \mathrm{C}$ : Pyrrolidine ( 1 equiv), $\mathrm{AcOH}$ ( 1 equiv), THF, $30{ }^{\circ} \mathrm{C}, 18 \mathrm{~h}$. 

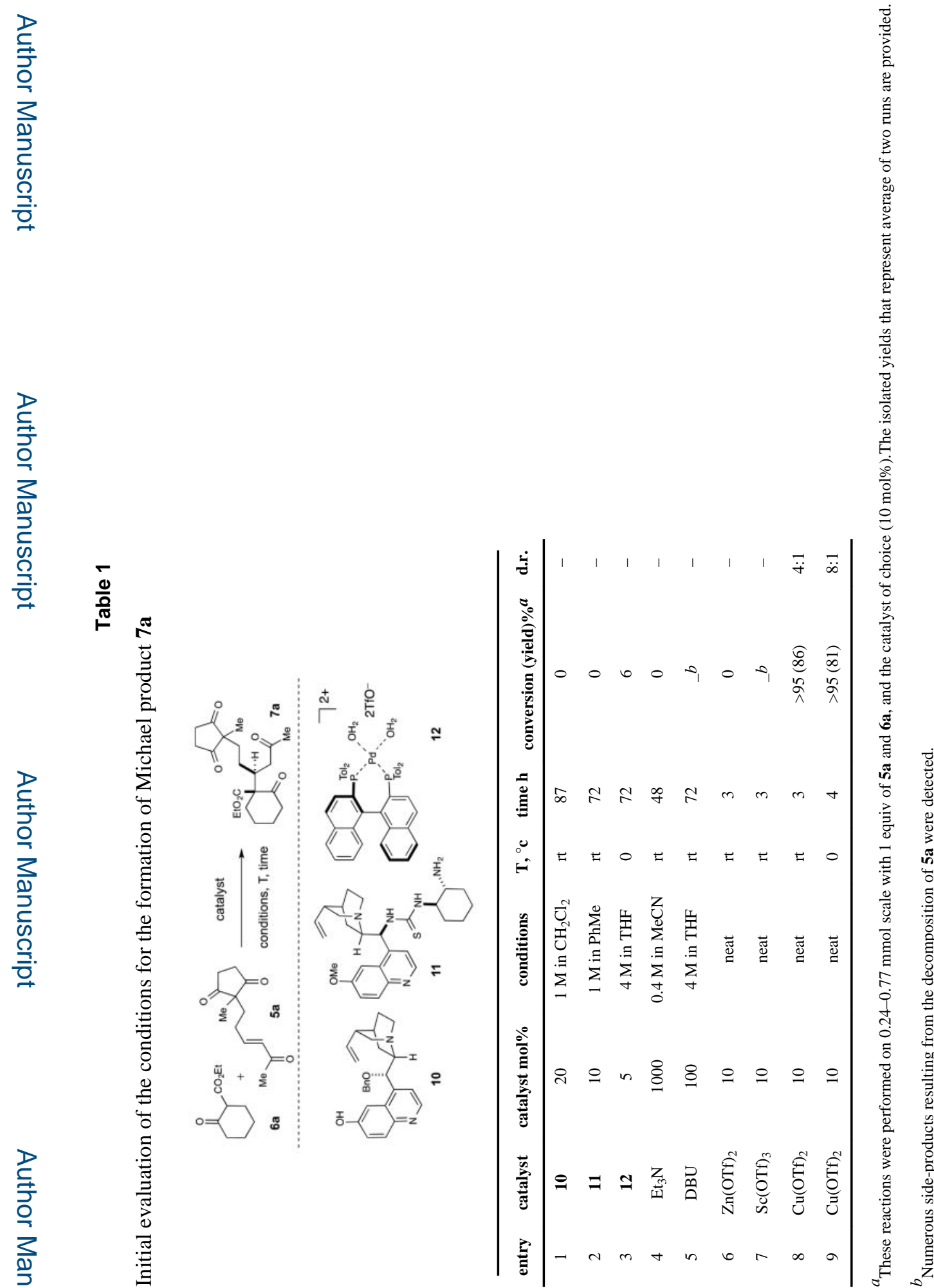

J Am Chem Soc. Author manuscript; available in PMC 2015 November 18. 


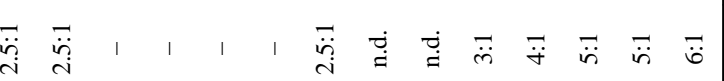

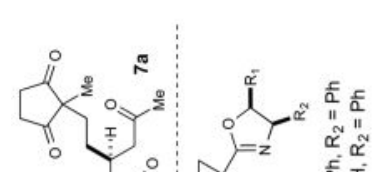




\section{Table 3}

\section{Double aldol cyclization studies ${ }^{a}$}

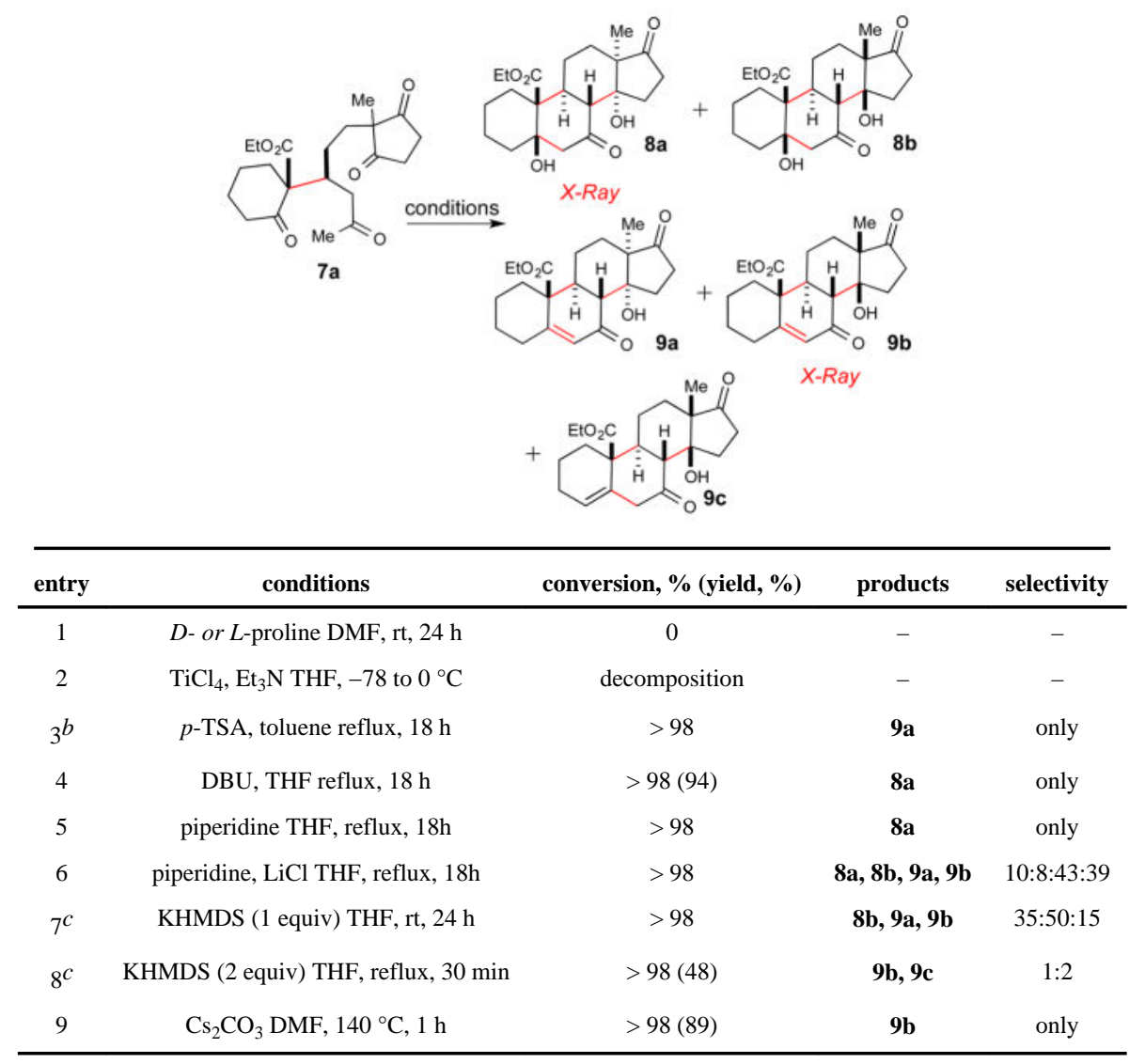

${ }^{a}$ Pre-purified diastereomerically pure $7 \mathbf{a}$ was used for these studies.

${ }^{b}$ Unidentified product (c.a. 30\%) was formed along with $\mathbf{9 a}$;

${ }^{c}$ Significant amounts of retro-Michael reaction products were observed. 